\title{
Factors influencing dentists' choices of restorative materials in Saudi Arabia: a web-based online cross- sectional study
}

\author{
Lujain Hatem Alsughair ${ }^{1}$, Elsayeda Youssif ${ }^{2}$
}

${ }^{1}$ College of Dentistry, Qassim University, Buraydah, Qassim, Saudi Arabia

${ }^{2}$ Restorative Dentistry Specialist, Lecturer of Restorative Dentistry, Qassim University, Buraydah, Qassim, Saudi Arabia

\section{Type of article: Original}

\begin{abstract}
Background: There is a variety of restorative materials, from dental amalgam to the more recent introduction of resin and tooth-colored restorations, which makes choosing the most suitable restorative material a complex task for dentists. Dentists evaluate each case individually and make their selection decision based on several factors which have different degrees of clinical significance.

Objective: The aim of this study was to identify the patients' teeth, and dentist's factors related to the selection of restorative materials among dentists working in Saudi Arabia.

Methods: A web-based cross-sectional survey was conducted using simple random sampling method in Saudi Arabia in 2018. The questionnaire was adopted from other studies, which were pretested using pilot studies to ensure reliability. The questionnaire consisted of demographic data, multiple-choice questions measuring the most commonly used materials and the reasons behind that, along with 5-point Likert-scale questions identifying the attitudes of dentists regarding the factors influencing their choices of restorative materials. The questionnaire was completed by 229 dentists. Using IBM-SPSS version, the data were analyzed in descriptive statistics and Chi square test. A p-value of less than 0.05 was considered statistically significant in examining the study hypotheses. Results: Composite was the most commonly used material to restore primary carious lesions in class I, class II and class V. Conservative preparation was the main reason for using composite (55.9\%). Esthetics was the main limitation of using amalgam (52\%). The number of male dentists not using amalgam was significantly higher than their female peers $(\mathrm{p}=0.032)$.

Conclusion: The trend of using composite is increasing in Saudi Arabia and has been reported worldwide in various conditions even in the more challenging circumstances such as large cavities and molars, mainly because its preparation is conservative. However, composite is still not preferred for patients with high caries activity and poor oral hygiene. Further research is required to negotiate more factors such as the material factors and socioeconomic status of the patient.
\end{abstract}

Keywords: Factors, Composite, Amalgam, Material, Restorative

\section{Introduction}

With the increasing introduction of recent restorative materials, selecting materials has become an important part of the dentists' decision-making process. For some time, amalgam had been the most commonly used restorative material for posterior teeth until its use declined five decades ago (1). Despite the fact that amalgam is unaesthetic, the decline in the use of amalgam was attributed to the concern over its mercury toxicity. However, a randomized clinical trial concluded that the amount of daily absorbed amalgam-related mercury is below the tolerable level established by the World Health Organization (WHO) (2). Furthermore, amalgam requires more tooth preparation for retention and that is against the conception of conservative dentistry, which made resin composite and other tooth-colored restorations gain more space in conservative dentistry (3). Three European Union institutions (the

\section{Corresponding author:}

Lujain Hatem Alsughair, College of Dentistry, Qassim University, Buraydah, Qassim, Saudi Arabia.

Email: lujain.alsughair@qudent.org

Received: July 06, 2018, Accepted: August 22, 2018, Published: November 2018

iThenticate screening: July 30, 2018, English editing: September 01, 2018, Quality control: September 01, 2018

This article has been reviewed / commented by three experts

Ethics approval: EA/5010/2018 (Qassim University)

(C) 2018 The Authors. This is an open access article under the terms of the Creative Commons Attribution-NonCommercialNoDerivs License, which permits use and distribution in any medium, provided the original work is properly cited, the use is non-commercial and no modifications or adaptations are made. 
European Parliament, European Commission and the Council of the European Union) have agreed to enact a ban on dental amalgam fillings use in children under 15 years old and in pregnant and breastfeeding women (4). However, the American Dental Association still supports the use of amalgam and considers it safe (5). When the polymerizing resin restorations were introduced in the 1950s, they opened up new avenues for dentists and, ever since, remained one of the most frequently used treatments in restorative dentistry (6). Composite was welcomed in due to its advantages including minimal tooth preparation, being tooth-colored, more esthetic, and well-bonding to the conditioned tooth surface (7). However, resin composite has drawbacks in which amalgam succeeds to achieve, such as marginal leakage, secondary caries, poor load bearing ability, high wear rate, and inability to restore the contact in class II restorations (8). A prospective study following a group of Brazilian people revealed that the caries activity, tooth type and size of the cavity are associated with the choice of restorative material, while the socioeconomic status of the patient did not show any association (9). In a survey conducted in Northern Saudi Arabia, private dental practitioners used composite to replace well-placed amalgam more frequently than dentists working in the public health services, which might be attributed to their marketing orientation (10). Composite is placed in premolars more than molars, and dentists with high years of experience ( $\geq 10$ years) used composite less frequently than dentists with less years of experience (1). Most of the restorations received by male patients are more likely to be amalgam (11). Furthermore, there is a lack of knowledge and research regarding the views and opinions of dentists working in Saudi Arabia about the factors that influence their choices of restorative materials. Therefore, the aim of this study was to identify the patients' teeth and dentist's factors related to the selection of restorative materials among dentists working in Saudi Arabia.

\section{Material and Methods}

\subsection{Research design and participants}

A cross-sectional study using a self-administered questionnaire was conducted among dentists working in Saudi Arabia between January 21, 2018 and March 1, 2018. Regarding the inclusion and exclusion criteria, the study included the dentists who answered "Always," "Often" or "Sometimes" to the question that measured the extent of dealing with caries diagnosis and treatment. Those who answered "Rarely" were excluded. Six hundred dentists were emailed to participate in the questionnaire using the general dental practitioners emailing list of the Saudi Dental Society which includes dentists from all over Saudi Arabia.

\subsection{Sampling}

It would be very difficult to divide the country into clusters and retrieve emails from each region (there ae no available resources to take the emails from), therefore, we used simple random sampling method as the best method for such studies, to collect responses from dentists working in the public health service, private sector and other sectors such as the academic institutions in Saudi Arabia. We used the email list of the Saudi Dental Society -GDPs. The emailing list includes 600 dentists, which represents a relatively high percentage of the working dentists in Saudi Arabia.

\subsection{Instrument}

A self-administered questionnaire was constructed and adopted from similar studies by Simen E Kopperud (12) as well as another survey used by Fahad Alkhodairy, with slight modifications to the questions in order to serve the purpose of this study. The two questionnaires were pretested using pilot studies to ensure reliability $(12,13)$. The questionnaire included demographic data (age, gender, work experience, and practice sector), 5-point Likert-scale questions regarding the factors influencing the choices of restorative materials, as well as multiple choice questions regarding which restorative material the dentist would use most frequently in clinical cases of class I, class II and class $\mathrm{V}$. Views on the main reason of using resin composite and amalgam were also sought.

\subsection{Data collection}

The questionnaire was e-mailed to 600 general dental practitioners (GDPs) registered in the Saudi Dental Society, which is a leading dental association in Saudi Arabia. An emailing list of the GDPs in the Saudi Dental Society was used to send the questionnaire to the participants from the period of January 21, 2018 to March 1, 2018. The questionnaire was formulated using Google Forms, and sent as a hyperlink for one time without reminding emails. The purpose of using Google Forms was to guarantee the security of the collected data, prevent the potential of virus spread to participants' computers, and for the reliability of the system.

\subsection{Statistical analysis}

The responses of the participants were processed using IBMC SPSSC Statistics version 23 (IBMC Corp., Armonk, NY, USA). Percentages were used as well as Chi square test and Kruskal-Wallis test, to compare differences in distribution between groups. P-values of less than 0.05 were considered statistically significant. 


\subsection{Ethics of online medical research}

The study was approved by the Ethical Committee and Research Centre of College of Dentistry, Qassim University (Ref: EA/5010/2018). Confidentiality of the participants was maintained as no names or work places were included in the demographic data. Participation was voluntary with written informed consent at the beginning of the questionnaire (an information sheet was included in the inviting email explaining the purpose of the study, the study topic, identities of the main researchers, and mentioning that the privacy of the participants and the confidentiality of their information are respected in the study). For insuring there was no potential virus spread (as it is possible in online surveys), we used Google Forms as the infrastructure of our web-based survey.

\section{Results}

A total of 238 dentists completed the questionnaire in which 139 of them were male dentists and 99 were female. Nine dentists were excluded according to the exclusion criteria, so we were left with 229 participants. The response rate was $38 \%$, which is considered acceptable in web based surveys. Most of the participants $(54.1 \%)$ worked in the public health service, $34.5 \%$ were in the private sector and $11.4 \%$ worked in other sectors such as the academic institutions, and these figures relatively represent the distribution of dentists across these working sectors in Saudi Arabia. Resin composite was found to be the most commonly used restorative material when restoring primary caries confined the to the outer half of dentin in class I, class II and class V. Amalgam was the second most frequently used material for class II. Resin-modified glass ionomer was the second most commonly used material for class I and class $\mathrm{V}$ as it was chosen by 66 dentists $(28.8 \%)$ to be used for class $\mathrm{V}$ restorations and by 12 dentists $(5.2 \%)$ for class I. Table 1 demonstrates the percentages of the restorative materials used for restoring primary caries confined to the outer surface of dentine in class I, Class II and class V.

Table 1. Percentages of restorative materials used to restore primary caries confined to the outer dentin surface in class I, class II and class V as well as rationale of using composite and limiting amalgam.

\begin{tabular}{|c|c|c|c|}
\hline \multirow[t]{18}{*}{ Restorative materials usage } & \multirow[t]{6}{*}{ Class I } & Composite & $88.2 \%$ \\
\hline & & Amalgam & $3.9 \%$ \\
\hline & & Compomer & $1.7 \%$ \\
\hline & & RMGI & $5.2 \%$ \\
\hline & & Indirect restorations & $0 \%$ \\
\hline & & Other & $0.9 \%$ \\
\hline & \multirow[t]{6}{*}{ Class II } & Composite & $85.2 \%$ \\
\hline & & Amalgam & $7.9 \%$ \\
\hline & & Compomer & $1.3 \%$ \\
\hline & & RMGI & $3.5 \%$ \\
\hline & & Indirect restorations & $1.3 \%$ \\
\hline & & Other & $0.8 \%$ \\
\hline & \multirow[t]{6}{*}{ Class V } & Composite & $68.2 \%$ \\
\hline & & Amalgam & $0 \%$ \\
\hline & & Compomer & $3.9 \%$ \\
\hline & & RMGI & $28.8 \%$ \\
\hline & & Indirect restorations & $0 \%$ \\
\hline & & Other & $0 \%$ \\
\hline \multirow{12}{*}{$\begin{array}{l}\text { Rationale of using composite and limiting } \\
\text { amalgam. }\end{array}$} & \multirow{4}{*}{$\begin{array}{l}\text { Main reason that limits the use of } \\
\text { amalgam }\end{array}$} & Esthetic & $52 \%$ \\
\hline & & Patient's desire & $16.2 \%$ \\
\hline & & Mercury hazards & $16.2 \%$ \\
\hline & & Other reasons & $15.7 \%$ \\
\hline & \multirow[t]{4}{*}{ Main reason for using composite } & $\begin{array}{l}\text { Conservative } \\
\text { preparation }\end{array}$ & $55.9 \%$ \\
\hline & & Esthetic & $7.4 \%$ \\
\hline & & Patient's desire & $30.1 \%$ \\
\hline & & Other reasons & $6.5 \%$ \\
\hline & \multirow[t]{2}{*}{ Using amalgam for large cavities } & Yes & $58.1 \%$ \\
\hline & & No & $41.9 \%$ \\
\hline & \multirow[t]{2}{*}{ Using amalgam for small cavities } & Yes & $95.6 \%$ \\
\hline & & No & $4.4 \%$ \\
\hline
\end{tabular}


Gender of the dentist was statistically associated with the use of amalgam, as more of the male dentists did not use amalgam in their clinical practice, neither in the small cavities nor the large ones compared to their female peers $(p=0.032)$. Age, years of experience and type of practice were not statistically significant $(p=0.07, p=0.16, p=0.68$ respectively). Esthetics was the most common factor for the limitation of using amalgam (52\%). Resin composite was mainly used because of the advantage of conservative preparation (55.9\%). Table 1 demonstrates the usage of restorative materials in class I, class II and class V to restore primary caries confined to the outer dentin surface as well as the rationale of using and limiting composite and amalgam. The number of dentists working in public health who agree that the desire of the patient for a certain material plays a role in the selection process is more statistically significant than those working in the private sector and academic institutions. There is a statistically significant association between the gender of the dentists and their belief that composite is not suitable for patients with high caries activity, as more male dentists agreed with this statement. Table 2 shows the attitudes of dentists regarding the patient and tooth factors influencing the selection of restorative materials respectively.

Table 2. Attitudes of the respondents regarding the patient factors influencing the selection of restorative materials.

\begin{tabular}{|c|c|c|c|}
\hline \multirow{2}{*}{$\begin{array}{l}\text { Studied } \\
\text { factors }\end{array}$} & \multirow[t]{2}{*}{ Statement } & \multicolumn{2}{|c|}{ Significance } \\
\hline & & Variable & p-value \\
\hline \multirow[t]{21}{*}{ Patient factor } & \multirow[t]{3}{*}{ Composite is not suitable for patients with high caries activity } & Age & 0.193 \\
\hline & & Gender & $0.018 *$ \\
\hline & & Practice & 0.202 \\
\hline & \multirow[t]{3}{*}{ Composite is not suitable for patients with bad oral hygiene } & Age & 0.418 \\
\hline & & Gender & 0.62 \\
\hline & & Practice & 0.118 \\
\hline & \multirow[t]{3}{*}{ Amalgam is not suitable for young patients } & Age & 0.425 \\
\hline & & Gender & 0.61 \\
\hline & & Practice & 0.335 \\
\hline & \multirow[t]{3}{*}{ Amalgam is not esthetically acceptable to be used for female patients } & Age & 0.724 \\
\hline & & Gender & 0.068 \\
\hline & & Practice & 0.296 \\
\hline & \multirow[t]{3}{*}{ Composite is not suitable for patients with heavy bite } & Age & 0.918 \\
\hline & & Gender & 0.99 \\
\hline & & Practice & 0.451 \\
\hline & \multirow{3}{*}{$\begin{array}{l}\text { The patient's desire for a certain material plays a role in the restoration } \\
\text { selection }\end{array}$} & Age & 0.556 \\
\hline & & Gender & 0.69 \\
\hline & & Practice & $0.045^{*}$ \\
\hline & \multirow[t]{3}{*}{ Amalgam has occupational and environmental hazards } & Age & 0.854 \\
\hline & & Gender & 0.47 \\
\hline & & Practice & 0.412 \\
\hline \multirow[t]{9}{*}{ Tooth factors } & \multirow[t]{3}{*}{ Composite is not suitable for molars } & Age & 0.119 \\
\hline & & Gender & 0.412 \\
\hline & & Practice & 0.665 \\
\hline & \multirow[t]{3}{*}{ Composite is only suitable for small cavities } & Age & 0.48 \\
\hline & & Gender & 0.37 \\
\hline & & Practice & 0.84 \\
\hline & \multirow[t]{3}{*}{ Composite is a good alternative to amalgam } & Age & 0.166 \\
\hline & & Gender & 0.176 \\
\hline & & Practice & 0.533 \\
\hline
\end{tabular}

* Values show statistical significance at the $\mathrm{p}<0.05$

\section{Discussion}

\subsection{Frequently used restorative materials}

The present findings show remarkable tendency to the use of tooth-colored restorative materials in most circumstances. The use of amalgam is gradually being replaced by resin composite mainly due to patient and dentist related factors (14). Moreover, the text of the Minamata Convention on Mercury promotes the use of cost-effective and mercury-free alternatives for dental restorations, restricts amalgam to its encapsulated form only, and 
encourages safe environmental practices (15). Most of the dentists in this study believed that composite is a good alternative to amalgam and that is in accordance with the findings of Simen E Kopperud (12). However, some dentists in Saudi Arabia still use amalgam in the challenging cases of posterior teeth. Composite was the predominant material used to restore primary caries in this study, which is similar to what Simen E Kopperud found in his study that composite is the material of choice in restoring mesio-occluso-distal (MOD) cavities (13). Conservative cavity preparation was found to be the most common reason for using composite in a previous survey conducted in Northern Saudi Arabia and that is consistent with the reason found in our study, since conservative dentistry is the main trend (10). However, Glimmer AS revealed that patient preference is the main reason for using composite, followed by conservative procedure, as patient satisfaction is a major priority in some practices (16). A previous study showed that esthetics is the main limitation for the use of amalgam, which is similar to the results of the present study as the emphasis on appearance and esthetics cannot be underestimated nowadays (13).

\subsection{Patient factors}

In the Simen E Kopperud questionnaire, most of the dentists disagreed that composite is not suitable for patients with poor oral hygiene and high caries activity, which is contrary to the results of this study (12). A study in Sweden revealed that patients with high caries activity had lower composite longevity rates compared to those with moderate and low caries activity, another study also showed that amalgam was more frequently used than composite in patients with bad oral hygiene and high caries risk $(17,18)$. Most dentists agreed that amalgam is esthetically not acceptable to be used for female patients, which is similar to previous findings as significantly fewer female patients received amalgam than male patients, also patients older than 16 years old received more amalgam than patients 14 years old or younger. Another study showed that $25 \%$ of the restorations received by adolescents were amalgam, $30 \%$ were composite and $42 \%$ were glass ionomer. However, most of the dentists in the present study disagreed with the statement that amalgam is not suitable for young patients $(19,20)$.

\subsection{Tooth factors}

Most of the respondents disagreed that composite is not suitable for molars. However, the frequency of using composite in premolars is still more than in molars, as has been reported in previous studies, which might be due to the involvement of premolars in the esthetic zone and smiles of some people (18). Moreover, another published study reported that the frequency of placing amalgam was 5 times greater in molars than in premolars (9). Most of the participating dentists disagreed with the statement that composite is only suitable for small cavities. In the past, using composite was mainly limited to small cavities. A recent study comparing the survival of amalgam and composite, however, revealed better performance of composite restorations in comparison to amalgam for large cavities (21).

\subsection{Clinician factors}

Fahad Alkhodairy found that significantly more dentists working in private sectors use amalgam less frequently than those in the public health, but that is inconsistent with the results of our study, which did not find any statistical significance between the use of amalgam and the type of practice (13). In a cross-sectional study conducted in 2011, the majority of the restorations placed by female practitioners were amalgam, which is similar to the present findings (11).

\subsection{Study strength and limitation}

One of the strengths of the study was using the web-based survey, which has advantages over traditional paperbased surveys in terms of confidentiality of sensitive information of participants, the ease of use, and decreasing the possibilities of receiving incomplete questionnaires. The study shed light on a topic which has been given little attention in the field of research in Saudi Arabia. However, restorative dentists would have been a better-targeted population than general practitioners as they consider these factors more often, but we were unable to reach a large group of restorative dentists in Saudi Arabia. The relatively small study sample is another limitation. However, other factors can be involved in future research such as the material factors (In terms of properties and ease of use) and the patients' socioeconomic status.

\section{Conclusions}

The trend of using composite is increasing in Saudi Arabia and has been reported worldwide in various conditions even in the challenging ones such as large cavities and molars, mainly because its preparation is conservative. However, composite is still not preferred for patients with high caries activity and poor oral hygiene. Male dentists use amalgam less frequently than their female peers do, and amalgam seems to be esthetically not acceptable for 
female patients. The majority of dentists believe in the occupational and environmental hazards of amalgam. Further research is required to negotiate more factors such as the material factors and the socioeconomic status of the patient.

\section{Acknowledgments:}

This study was the graduation project of the first author (Lujain Hatem Alsughair). The authors would like to extend their sincere gratitude to the College of Dentistry at Qassim University (Saudi Arabia) for their support throughout this work.

\section{Conflict of Interest:}

There is no conflict of interest to be declared.

\section{Authors' contributions:}

Both authors contributed to this project and article equally. Both authors read and approved the final manuscript.

\section{References:}

1) Ben-Gal G, Weiss EI. Trends in material choice for posterior restorations in an Israeli dental school: composite resin versus amalgam. J Dent Educ. 2011; 75(12): 1590-5. PMID: 22184598.

2) Halbach S, Vogt S, Köhler W, Felgenhauer N, Welzl G, Kremers L, et al. Blood and urine mercury levels in adult amalgam patients of a randomized controlled trial: interaction of $\mathrm{Hg}$ species in erythrocytes. Environ Res. 2008; 107: 69-78. doi: 10.1016/j.envres.2007.07.005. PMID: 17767927.

3) Lynch CD, Opdam NJ, Hickel R, Brunton PA, Gurgan S, Kakaboura A, et al. Guidance on posterior resin composites: Academy of Operative Dentistry - European Section. Journal of Dentistry. 2014; 42(4): 377 383. doi: 10.1016/j.jdent.2014.01.009. PMID: 24462699.

4) Sarah Handzel, BSN, RN. EU Bans Dental Amalgam Use in Children, Pregnant and Breastfeeding Women. 2017.

5) American Dental Association Council on Scientific Affairs. Statement on dental amalgam, rev. 2009.

6) Bohaty BS, Ye Q, Misra A, Sene F, Spencer P. Posterior composite restoration update: focus on factors influencing form and function. Clin Cosmet Investig Dent. 2013; 5: 33-42. doi: 10.2147/CCIDE.S42044. PMID: 23750102, PMCID: PMC3666491.

7) Cenci M, Demarco F, de Carvalho R. Class II composite resin restorations with two polymerization techniques: relationship between microtensile bond strength and marginal leakage. J Dent. 2005; 33(7): 603-10. doi: 10.1016/j.jdent.2005.01.001. PMID: 16005800.

8) Burke FJ, McHugh S, Hall AC, Randall RC, Widstrom E, Forss H. Amalgum and composite use in UK general dental practice in 2001. Br Dent J. 2003; 194(11): 613-18. doi: 10.1038/sj.bdj.4810258. PMID: 12819697.

9) Correa MB, Peres MA, Peres KG, Horta BL, Barros AD, Demarco FF. Amalgam or composite resin? Factors influencing the choice of restorative material. journal of dentistry. 2012; 40(9): 703-10. doi: 10.1016/j.jdent.2012.04.020. PMID: 22546263.

10) Iftikar Akbar. Knowledge and Attitudes of General Dental Practitioners Towards Posterior Composite Restorations in Northern Saudi Arabia. Journal of Clinical and Diagnostic Research. 2015; 9(2): ZC61 ZC64. doi: 10.7860/JCDR/2015/11843.5610. PMID: 25859528, PMCID: PMC4378811.

11) Makhija SK, Gordan VV, Gilbert GH, Litaker MS, Rindal DB, Pihlstrom DJ, et al. Practitioner, patient, and caries lesion characteristics associated with type of material: findings from The Dental Based-Research Network. J Am Dent Assoc. 2011; 142(6): 622-32. PMID: 21628683, PMCID: PMC3107519.

12) Kopperud SE, Staxrud F, Espelid I, Tveit AB. The Post-Amalgam Era: Norwegian Dentists' Experiences with Composite Resins and Repair of Defective Amalgam Restorations. International Journal of Environment Research and Public Health. 2016; 13(4): 441. doi: 10.3390/ijerph13040441. PMID: 27110804, PMCID: PMC4847103.

13) Fahad AK. Attitudes of dentists and interns in Riyadh to the use of dental amalgam. BMC. 2016. doi: 10.1186/s13104-016-2294-x. PMID: 27855718, PMCID: PMC5114813.

14) Sunnegardh-Gronberg K, van Dijken JW, Funegard U, Lindberg A, Nilsson M. Selection of dental materials and longevity of replaced restorations in Public Dental Health clinics in northern Sweden. J Dent. 2009; 37(9):673-78. doi: 10.1016/j.jdent.2009.04.010. PMID: 19477572.

15) Mercury convention. Minamata convention on mercury. 2013. 
16) Gilmour AS, Latif M, Addy LD, Lynch CD. Placement of posterior composite restorations in United Kingdom dental practices: techniques, problems, and attitudes. Int Dent J. 2009; 59(3): 148-54. PMID: 19637523.

17) Sunnegårdh-Grönberg K, van Dijken JW, Funegård U, Lindberg A, Nilsson M. Selection of dental materials and longevity of replaced restorations in Public Dental Health clinics in northern Sweden. journal of dentistry. 2009; 37(9): 673-8. doi: 10.1016/j.jdent.2009.04.010. PMID: 19477572.

18) Khalaf ME, Alomari QD, Omar R. Factors relating to usage patterns of amalgam and resin composite for posterior restorations - a prospective analysis. journal of dentistry. 2014; 785-92. doi: 10.1016/j.jdent.2014.04.010. PMID: 24769386.

19) Vidnes-Kopperud S, Tveit AB, Gaarden T, Sandvik L, Espelid I. Factors influencing dentists' choice of amalgam and tooth-colored restorative materials for Class II preparations in younger patients. Acta Odontologica Scandinavica. 2009; 67(2): 74-9. doi: 10.1080/00016350802577800. PMID: 19085213.

20) Correa MB, Peres MA, Peres KG, Horta BL, Barros AD, Demarco FF. Amalgam or composite resin? Factors influencing the choice of restorative material. journal of dentistry. 2012; 40(9): 703-10. doi: 10.1016/j.jdent.2012.04.020. PMID: 22546263.

21) Opdam NJ, Bronkhorst EM, Loomans BA, Huysmans MC. 12-Year survival of composite vs. amalgam restorations. Journal of Dental Research. 2010; 89(10): 1063-7. doi: 10.1177/0022034510376071. Epub 2010 Jul 26. PMID: 20660797. 